\title{
Changing Ocean Conditions and Some Consequences for Juvenile Salmon Feeding in Coastal Waters
}

\author{
Richard D. Brodeur ${ }^{1}$ and Elizabeth A. Daly ${ }^{2}$ \\ ${ }^{1}$ Fish Ecology Division, Northwest Fisheries Science Center, National Marine Fisheries Service, NOAA, Newport, \\ OR 97365, USA \\ ${ }^{2}$ Cooperative Institute for Marine Resources Studies, Oregon State University, Newport, OR 97365, USA
}

Keywords: Chinook salmon, coho salmon, trophic ecology, ocean environment, California Current

The early marine juvenile stages of Pacific salmon (Oncorhynchus spp.) occur in coastal waters off the west coast of USA in early summer, during what has been termed a critical life-history phase. The dominant salmon species represented in this region are juvenile coho $(O$. kisutch) and Chinook $(O$. tshawytscha) salmon, but chum $(O$. keta), pink (O. gorbuscha), and sockeye (O. nerka) salmon, steelhead (O. mykiss) and cutthroat trout $(O$. clarkii) are found in lower abundances. Following a period of variable freshwater residence, these anadromous salmon enter a highly dynamic but generally productive coastal ocean ecosystem in the Northern California Current (NCC), where they grow quickly and put on reserves for their first winter at sea and subsequent adult life history stage.

The general feeding habits of many of these species has been greatly resolved based on NCC sampling over the past 40 years beginning in 1979, when juvenile salmon diets were first described in detail (Peterson et al. 1982). Chinook, followed by coho, steelhead, cutthroat and sockeye salmon tend to be most piscivorous (Brodeur and Pearcy 1990; Pearcy et al. 1990; Brodeur et al. 2007; Baldwin et al. 2008; Brodeur et al. 2013), with generally increasing reliance on fish prey through ontogeny (Daly et al. 2009). The remaining species are generally smaller at ocean entry and utilize a more varied diet of euphausiids, copepods and other invertebrate taxa and rarely fishes (Brodeur et al. 2007). Here we focus mainly on yearling Chinook and coho salmon since they comprise the bulk of the catches in coastal surveys over this time period. The stomach collections for this study come from two different sampling programs: salmon were collected from 1979 to 1985 during a purse seine survey conducted by Oregon State University and since 1998 were collected in a National Marine Fisheries Survey using surface trawl nets (see Peterson et al. 2010 for detailed sampling methods). Sampling was conducted from May through September but in this analysis, we examined mainly the June cruises which were the most consistently sampled time period for which we have diet data (all years represented for Chinook and all but four for coho salmon).

The reliance on fish prey is seen in the diets of both species for most of the time period (Figs. 1 and 2), although notably in some years the prey consisted of a large proportion of invertebrate taxa, especially for coho salmon during several years. During this sampling period, the salmon have out-migrated into some very cool and productive ocean conditions (e.g., 1982, 1985, 1999, and 2008) but increasingly more warm and low production ocean conditions due to strong El Niño $(1983,1998,2010,2016)$ or low upwelling $(2005,2015$, and 2017) conditions in more recent years. These environmental changes resulted in dramatic shifts in diets sometimes in sequential summers. During cool ocean conditions, the diets of both species are dominated by fish taxa associated with cool waters and euphausiids, whereas during warm conditions, the diets consist primarily of offshore taxa such as juvenile northern anchovies, rockfishes, and hyperiid amphipods, all of which may be of lower trophic value.

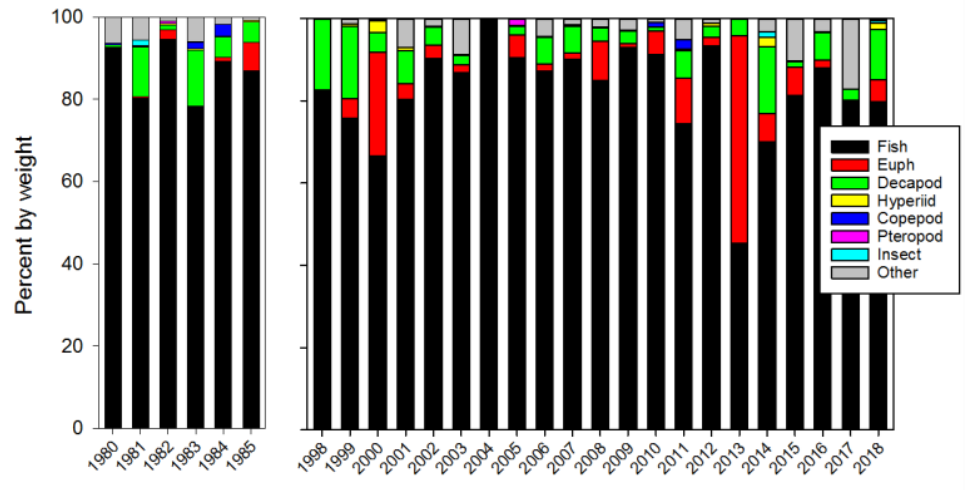

Fig. 1. Time series of June diets for yearling Chinook salmon analyzed from the 1980-1985 period (left panel) and the 1998-2018 period (right panel) by percent by weight of the major prey taxonomic categories. Sample sizes are 368 and 2033 stomachs for the earlier and later periods, respectively. All years have a minimum of 15 individuals analyzed. 


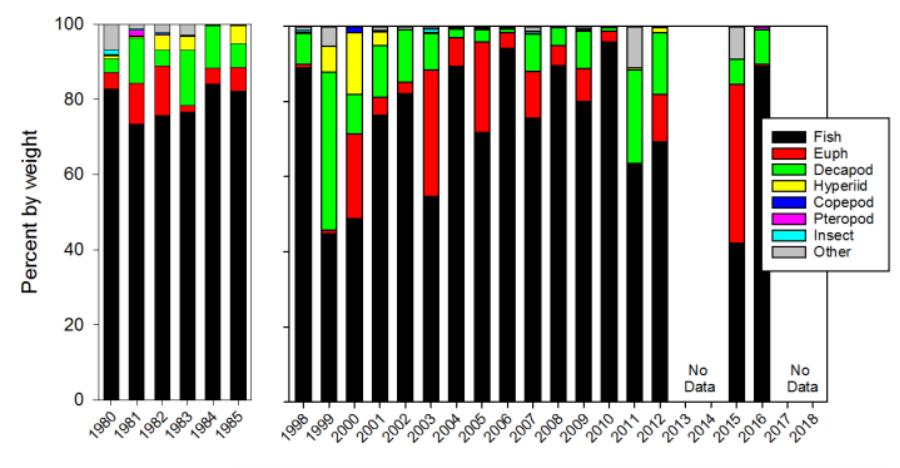

Fig. 2. Time series of June diets for yearling coho salmon analyzed from the 1980-1985 period (left panel) and the 1998-2016 period (right panel) by percent by weight of the major prey taxonomic categories. Sample sizes are 647 and 2466 stomachs for the earlier and later periods, respectively. All years shown have a minimum of 15 individuals analyzed.
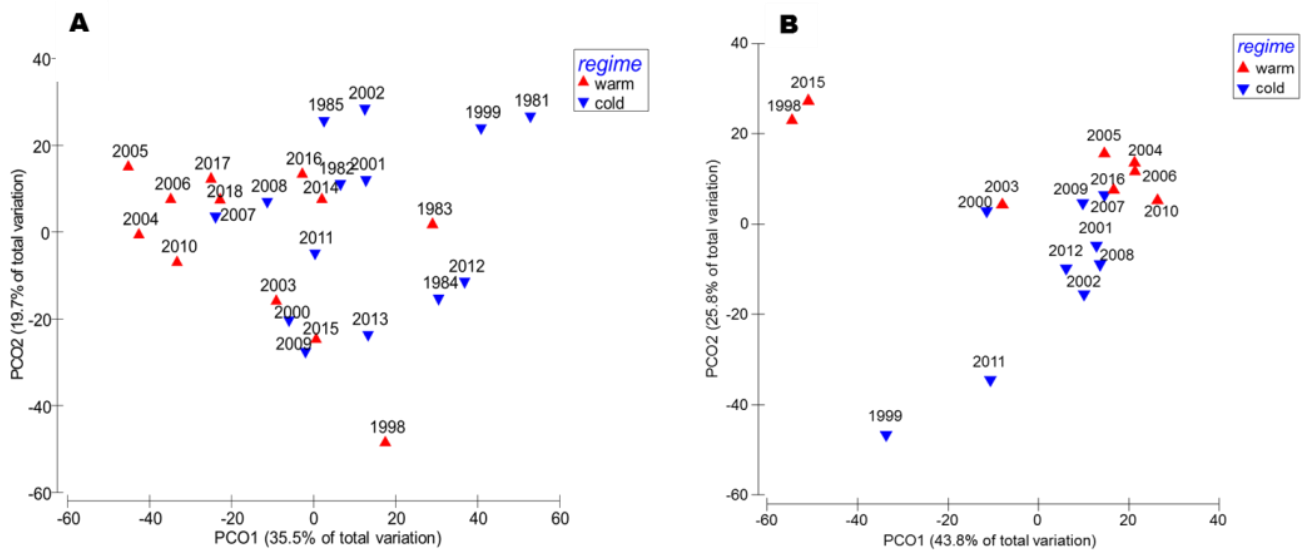

Fig. 3. Principal coordinate analysis (PCO) of juvenile yearling Chinook salmon (A) and coho salmon (B) diet composition. Years in blue were years with negative Pacific Decadal Oscillations (PDO) conditions, and years in red were years of positive PDO conditions. No 1980s data were available for coho salmon at the finer taxonomic resolution that was available for the later years.

An ordination of the diets based on the 20 top prey taxa (Daly et al. 2017) by year shows significant differences between cold and warm ocean years for Chinook salmon (ANOSIM between regime is $p=0.002$; Global; $R=0.254$ ) (Fig. 3a). Although the Chinook salmon diets in the recent (2015-2018) warm years were somewhat similar to those in other warm years (negative values on axis 1) (Fig. 3a), they were not found to be as extreme as an earlier warm period (2004-2006). Juvenile coho salmon showed less differentiation between warm and cold years $(p=0.038$; Global $R=0.119)$ and much of the variation was driven by a few extreme warm (1998 and 2015) and cold years (1999 and 2011; Fig. 3b).

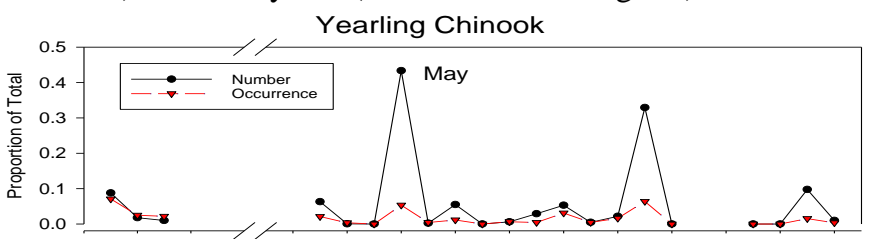

Fig. 4. Pteropods as a proportion of juvenile yearling Chinook salmon diets by number and occurrence by year and month.

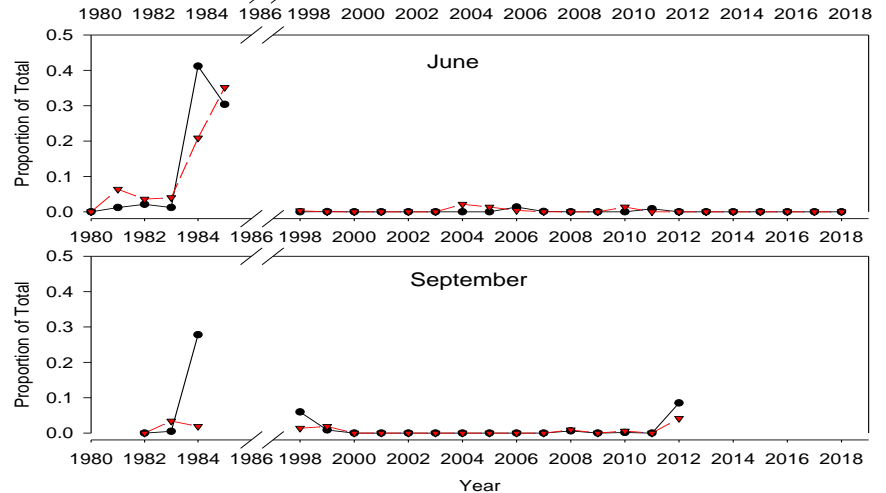


In addition to changing coastal preyscapes for juvenile salmon based on ocean temperature changes, we also observed long-term trends in specific taxa (declines in sand lance, smelt and euphausiids; increases in warm-water rockfishes and flatfishes). One notable example has been the declining utilization of some shelled mollusks (pteropods) in the recent years compared to the 1980-1985 period for both Chinook (Fig. 4) and coho (Fig. 5) salmon. Although warming ocean temperatures could be driving this change, it may be potentially related to changes in ocean chemistry due to increased greenhouse gas emissions. Pteropods are extremely vulnerable to ocean acidification and it has been shown that recent increase in acidic waters in the California Current may result in pteropod shell dissolution and eventual mortality (Bednaršek et al. 2014). Although pteropods may not have historically been as important to the mostly piscivorous species we examined compared to other more planktivorous salmon species (e.g., pink salmon, Armstrong et al. 2005), the loss of potential prey diversity could have consequences in terms of long-term survival of these salmon. Declines in $\mathrm{pH}$-sensitive taxa such as pteropods may be an early indicator for yet unobserved changes occurring in other salmon prey taxa such as crustaceans or fish due to increased ocean acidification.

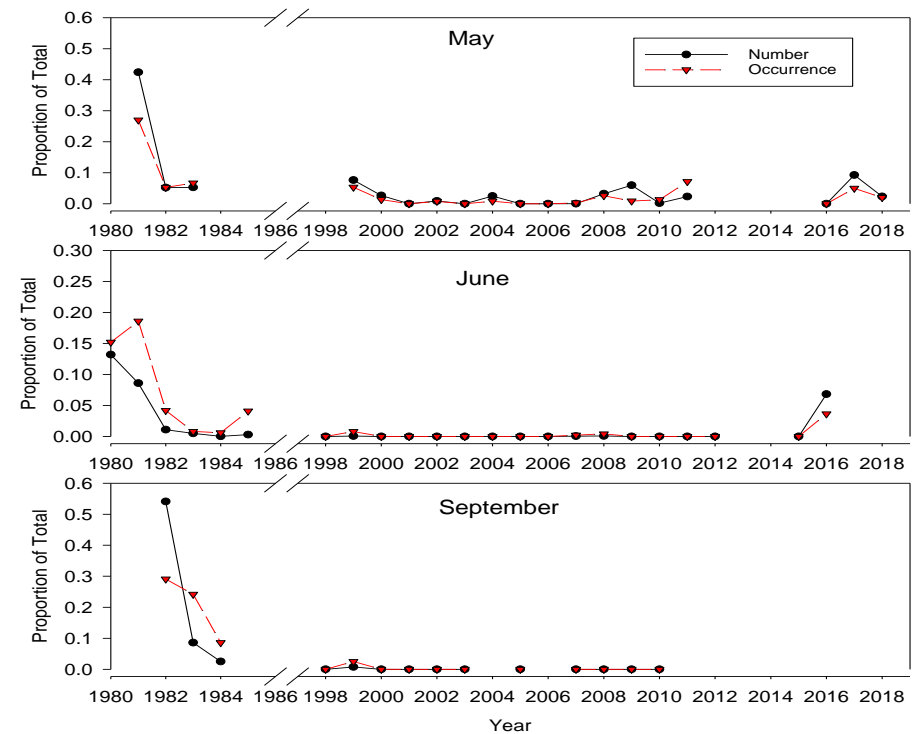

Fig. 5. Pteropods as a proportion of juvenile yearling coho salmon diets by number and occurrence by year and month.

In conclusion, juvenile Chinook and coho salmon are for the most part highly opportunistic predators and may serve as indicators and integrators of the changing ocean environment. Salmon show some changes related to the recent warm period, but they also appear to be able to switch to different prey as resource availability changes. In addition to changing abundance levels of prey, ocean warming may affect the timing or spatial distribution of key prey resources leading to a trophic mismatch (Siddon et al. 2013; Daly et al. 2017). Higher ocean temperatures also result in increased bioenergetic demands for higher consumption rates requiring more food to maintain the same metabolism (Daly and Brodeur 2015). Strong relationships exist between the diet composition of juvenile Chinook salmon in a given summer and the body condition and survival of that cohort in the ocean (Daly et al. 2017) such that diet information can provide a useful indicator of eventual salmon health and survival in coastal waters. We encourage continual monitoring of salmon feeding in coastal waters with a view towards understanding links between feeding success and survival in a rapidly changing ocean.

\section{REFERENCES}

Armstrong, J.L., J.L. Boldt, A.D. Cross, J.H. Moss, N.D. Davis, K.W. Myers, R.V. Walker, D.A. Beauchamp, and L.J. Haldorson. 2005. Distribution, size, and interannual, seasonal and diel food habits of northern Gulf of Alaska juvenile pink salmon, Oncorhynchus gorbuscha. Deep-Sea Res. II 52: 247-265.

Baldwin, R.E., T.W. Miller, R.D. Brodeur, and K.C. Jacobson. 2008. Expanding the foraging history of juvenile salmon: combining stomach-content and macroparasite-community analyses for studying marine diets. J. Fish. Biol. 72: 1268-1294.

Bednaršek, N., R.A. Feely, J.C.P. Reum, B. Peterson, J. Menkel, S.R. Alin, and B. Hales. 2014. Limacina helicina shell dissolution as an indicator of declining habitat suitability owing to ocean acidification in the California Current Ecosystem. Proc. Roy. Soc. Biol. Sci. 281: 20140123 
Brodeur, R.D., and W.G. Pearcy. 1990. Trophic relations of juvenile Pacific salmon off the Oregon and Washington coast. Fish. Bull. (U.S.) 88: 617-636.

Brodeur, R.D., S.S. Pool, and T.W. Miller. 2013. Prey selectivity of juvenile salmon on neustonic mesozooplankton in the northern California Current. N. Pac. Anadr. Fish Comm. Tech. Rep. 9:107-111. (Available at https://npafc.org)

Brodeur, R.D., E.A. Daly, M.V. Sturdevant, T. W. Miller, J.H. Moss, M. Thiess, M. Trudel, L.A. Weitkamp, J. Armstrong, and E.C. Norton. 2007. Regional comparisons of juvenile salmon feeding in coastal marine waters off the west coast of North America. Am. Fish. Soc. Symp. 57: 183-203.

Daly, E.A., R.D. Brodeur, and L.A. Weitkamp. 2009. Ontogenetic shifts in diets of juvenile and subadult Coho and Chinook salmon in coastal marine waters: important for marine survival? Trans. Am. Fish. Soc. 138:14201438 .

Daly, E.A. and R.D. Brodeur. 2015. Warming ocean conditions relate to increased trophic requirements of threatened and endangered salmon. PLoS One 10: 1-23.

Daly, E. A., R.D. Brodeur, and T.D. Auth. 2017. Anomalous ocean conditions in 2015: impacts on spring Chinook salmon and their prey field. Mar. Ecol. Prog. Ser. 566: 169-182.

Pearcy, W.G., R.D. Brodeur, and J.P. Fisher. 1990. Distribution and biology of juvenile cutthroat trout (Oncorhynchus clarki clarki) and steelhead (O. mykiss) in coastal waters off Oregon and Washington. Fish. Bull. (U.S.) 88: 697-711.

Peterson, W.T., R.D. Brodeur, and W.G. Pearcy. 1982. Food habits of juvenile salmon in the Oregon coastal zone, June 1979. Fish. Bull. (U.S.) 80: 841-851.

Peterson, W.T., C.A. Morgan, J.P. Fisher, and E. Casillas. 2010. Ocean distribution and habitat associations of yearling coho (Oncorhynchus kisutch) and Chinook (O. tshawytscha) salmon in the northern California Current. Fish. Oceanogr. 19: 508-525.

Siddon, E.C., T. Kristiansen, F.J. Mueter, K.K. Holsman, R.A. Heintz, and E.V. Farley. 2013. Spatial matchmismatch between juvenile fish and prey provides a mechanism for recruitment variability across contrasting climate conditions in the Eastern Bering Sea. PLoS One 8: e84526. 